\title{
Development of Wind Tunnel for Laboratory Wind Turbine Testing
}

\author{
Dale S. Dolan, Danny Zepeda, and Taufik Taufik
}

\begin{abstract}
This paper presents the development of a wind tunnel that will be used for wind turbine testing in a controlled environment. The prototype is designed to be able to provide wind speeds of up to $20 \mathrm{~m} / \mathrm{s}(\sim 43 \mathrm{mph})$ depending on the cross sectional area of the tunnel chamber. A 42 inch tube axial fan is driven by a $5 \mathrm{hp}$ induction motor using a variable frequency drive to allow continuously variable wind speeds from near zero up to the maximum wind speed. The fan is rated to produce $\sim 25,000$ CFM and the corresponding wind speed is therefore dependent on chamber cross sectional area. There will be two chamber sizes possible. One is $\mathbf{2 . 5}$ feet by 2.5 feet and the other is 3.25 feet by 3.25 feet. The larger cross section allows larger turbines to be tested while the smaller cross section allows higher wind speeds to be reached. The paper also describes some possible applications of the apparatus in the academic environment.
\end{abstract}

\section{INTRODUCTION}

It is difficult to assess and effectively demonstrate wind turbine behavior in the traditional undergraduate laboratory setting, as environmental conditions cannot be reproduced from one test to the next. Peak power tracking algorithms, power management, conversion strategies and turbine aerodynamic performance cannot be readily observed without field testing a turbine. To overcome this problem many have developed wind turbine emulators or wind turbine simulators to mimic the shaft torque that would be available on a turbine shaft [1-3]. This approach has a number of benefits such as allowing a larger turbine to be emulated and permitting repeatability of various environmental conditions for various performance studies. As shown in [4] an equivalent single wind speed can be used to represent a complex wind field such that the resultant torque appearing on the shaft is equivalent. However the downside is that an actual set of turbine blades cannot experience a real wind field nor can a student see a real wind turbine in action and make real-time measurements. The approach in this paper is to develop a lower cost wind tunnel where an Electrical Engineering student can make live measurements and studies can be conducted using a controlled wind source. The obvious down side is that it is difficult to make a considerable amount of wind without a large fan or large motor and create this wind field over a large cross sectional area. For the development of the wind tunnel a tradeoff was made between a large cross sectional area and high wind speeds. The wind tunnel is intended for use in the Cal Poly Sustainable Energy Lab as a tool for faculty and student research as well as a teaching tool to be used in selected courses from the electrical engineering, power and energy curriculum.

\section{WIND TUNNEL DEVELOPMENT}

The heart of the wind tunnel is a large tube axial fan with a 42 inch diameter (shown in Figure 1). This is capable of producing $\sim 25,000$ CFM when driven by a 5 hp motor (shown in Figure 2). The fan is belt driven by the 3 phase $208 \mathrm{~V}$ induction motor. The speed of the motor is controlled by a VFD (variable frequency drive), shown in Figure 3, that can be adjusted in $.01 \mathrm{~Hz}$ increments from $0-60 \mathrm{~Hz}$. With the appropriate gearing maximum wind speed is achieved at a speed of $880 \mathrm{rpm}$. The volume of air translates to wind speed according to the cross sectional area of the chamber into which it is contained. The setup has two possible cross sectional areas, one to maximize speed and the other to allow larger devices to be tested. The larger chamber has a dimension of 3.25 feet by 3.25 feet and the smaller chamber has a cross section of 2.5 feet by 2.5 feet. These correlate to maximum wind speeds of $\sim 14 \mathrm{~m} / \mathrm{s}(\sim 30 \mathrm{mph})$ for the large cross section and $\sim 20 \mathrm{~m} / \mathrm{s}(\sim 43 \mathrm{mph})$ for the smaller cross section. It is clear that even with a large fan that the winds speeds possible are limited as the cross sectional area increases significantly. As such it would be impractical to increase the size of the chamber much past the current design. The wind speeds that are possible are sufficient to allow an adequate testing of various wind energy capture devices, although these devices must be limited in size to fit within the limited size of the chamber. As an example one wind turbine that will be tested is the $400 \mathrm{~W}$ wind generator shown in Figure 4. 


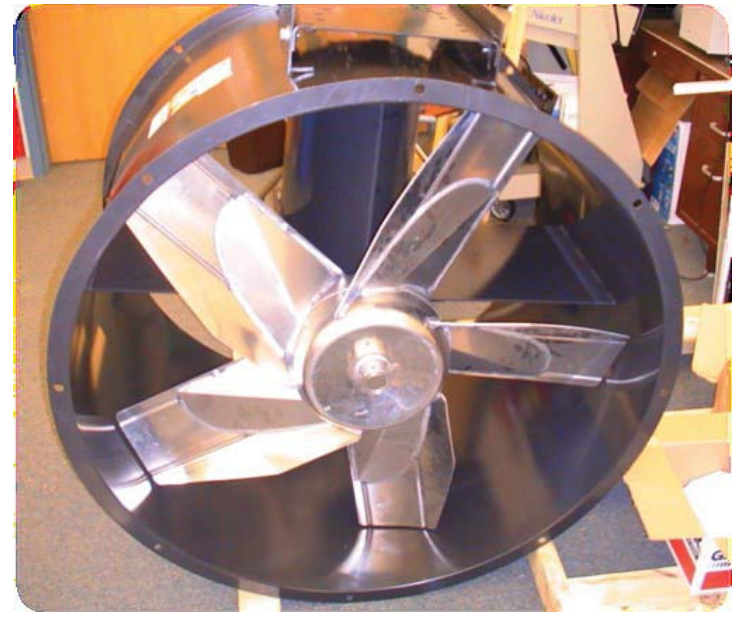

Figure 1. Dayton 42" Diameter, Belt Driven, Tube Axial Duct Fan. With 5 hp motor capable of 25,320 CFM.

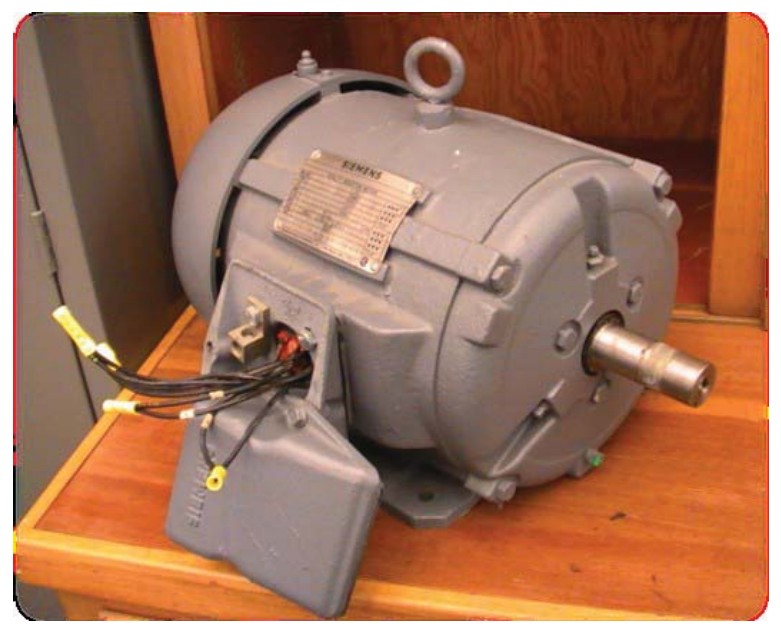

Figure 2. Siemens 3 phase induction motor: 5hp, 13.4/6.7 Amp, 230/460 V, 1740 rpm, NEMA B design, Frame 184T.

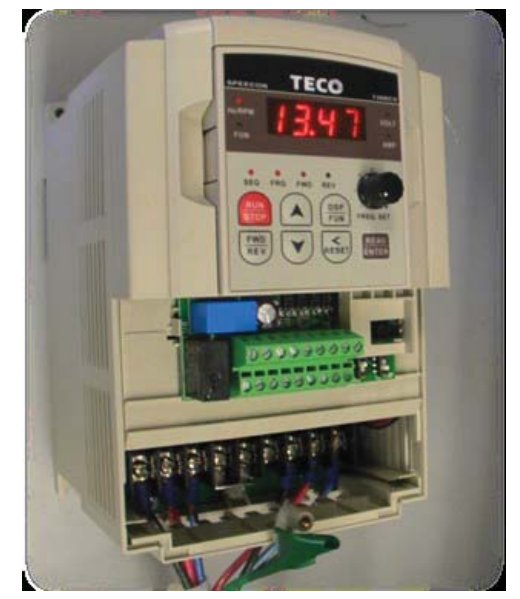

Figure 3. TECO Variable Frequency Drive, $5 \mathrm{hp} / 3.7 \mathrm{~kW}$, Input: 3-Phase, 200-240V, 20.5A, Output:3 phase 0-400Hz, 0-240V, 17.5 A

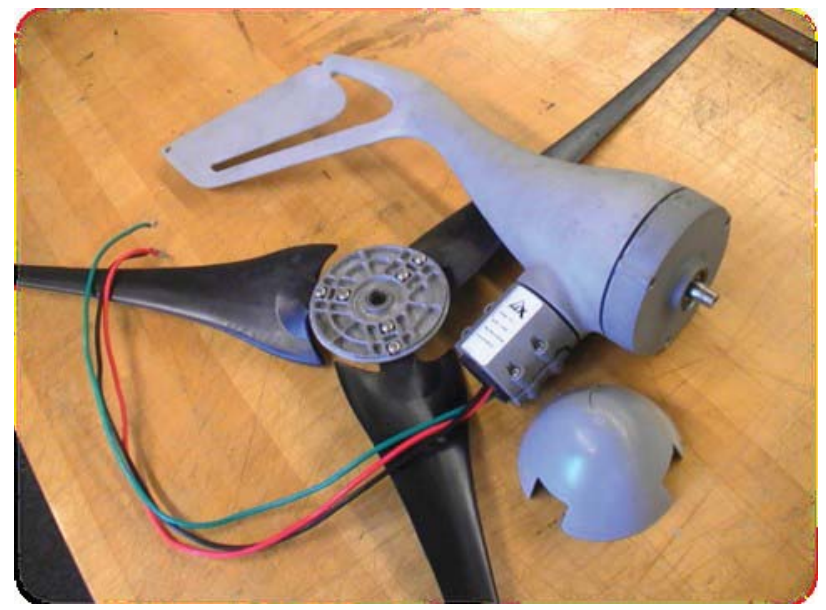

Figure 4. SunForce 400W Wind Generator. Peak output achieved at $28 \mathrm{mph}$ wind speed.

An AutoCAD sketch of the complete wind tunnel is shown from two perspectives in Figure 5 and Figure 6. The axial fan, the tunnel chamber and ducted adapter that connects the two pieces can be clearly seen in the two figures.

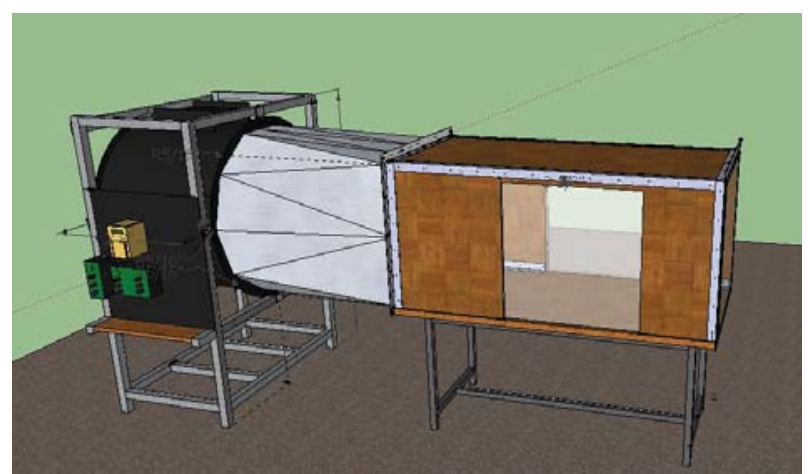

Figure 5. Wind Tunnel Autocad Drawing - View A

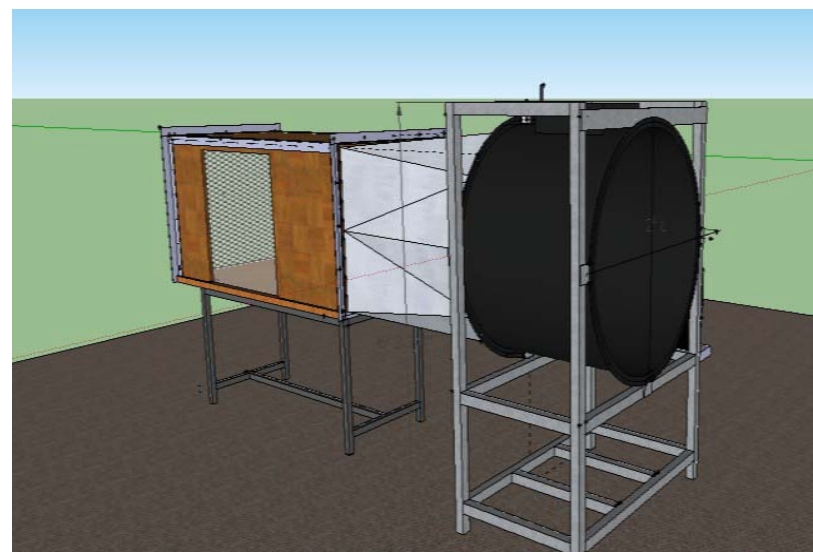

Figure 6. Wind Tunnel Autocad Drawing - View B

The wind tunnel is composed of two parts connected with a ducted adapter. It must be modular due to its size to allow transport from room to room when necessary. The first part is 
the motor stand. The AutoCAD view of this component is shown in Figure 7. The frame was constructed of over 70 feet of 2"x 2" -1/4"tubular steel. A photograph of the fan being installed in the completed frame is shown in Figure 8. The completed motor stand with both fan and motor installed underneath is shown in Figure 9.

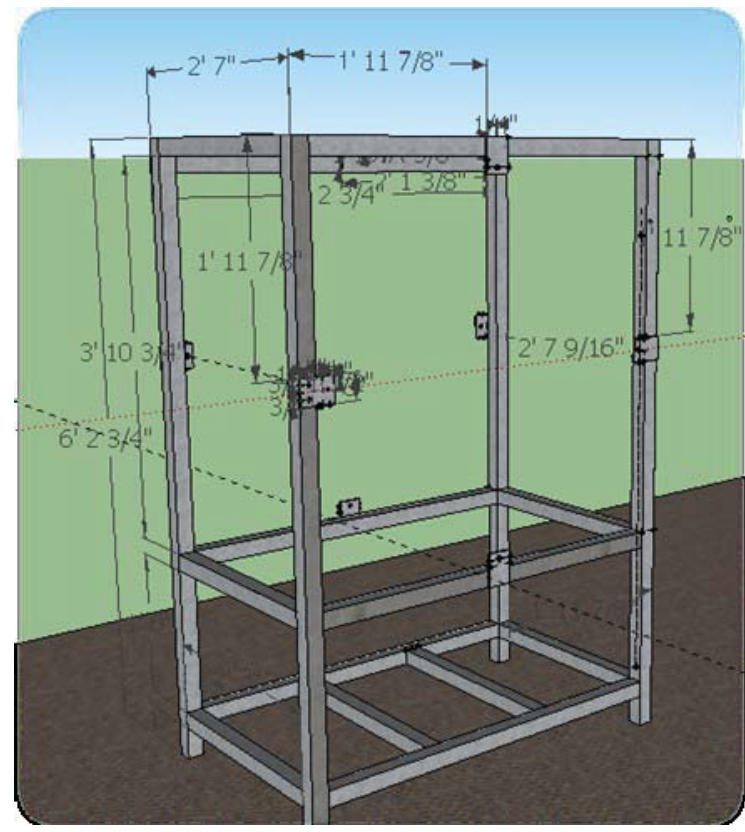

Figure 7. Motor Stand Autocad drawing

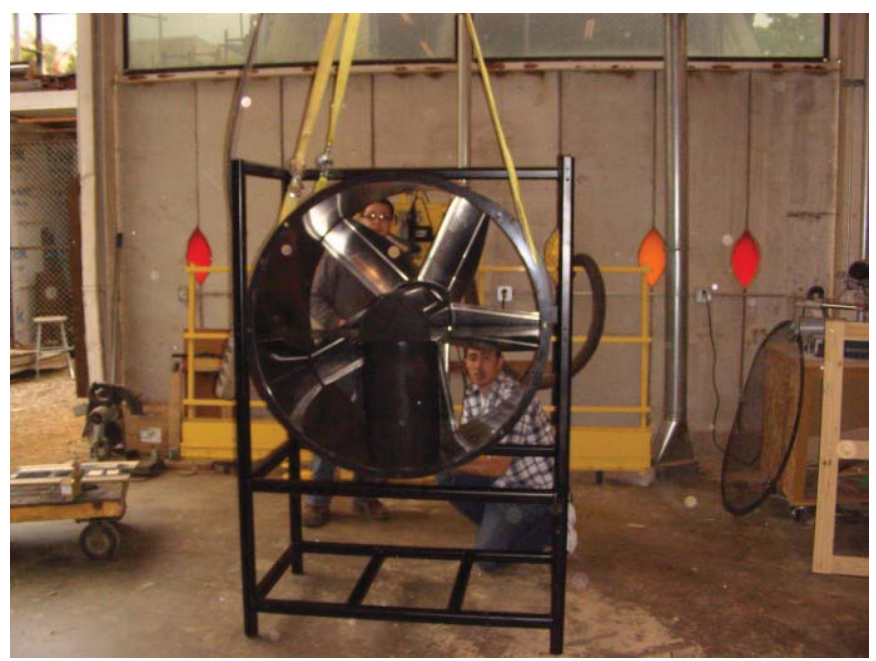

Figure 8. Installation of fan in motor stand.

The 2 inch tubular steel used in the construction of the motor stand weighs approximately 350 pounds. The entire structure with motor, fan and tubular steel has a final weight of $\sim 600$ pounds. Its completed dimensions are 44 inches in width and 66 inches in height. The height is such that the chamber will be at a suitable height for use, yet still fit through a standard door frame. Guards are installed on both sides of the fan for safety such that the fan cannot be touched and also such that items will not be sucked into the fan nor blown out causing potential damage to the setup or injury to the users. A close-up of the motor installed under the fan is seen in Figure 10.

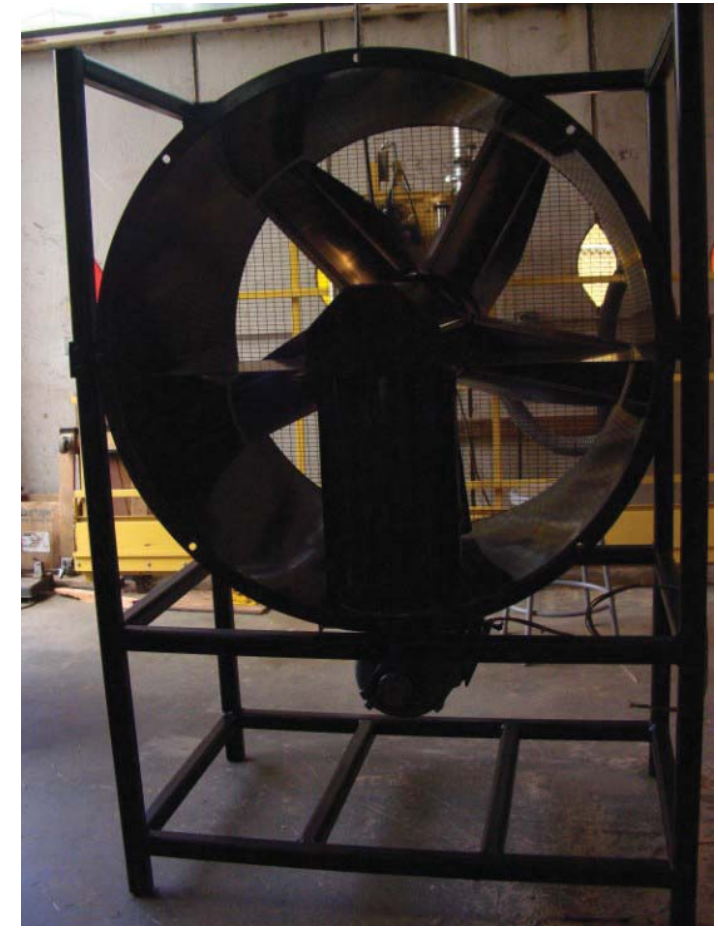

Figure 9. Completed nstallation of fan in motor stans

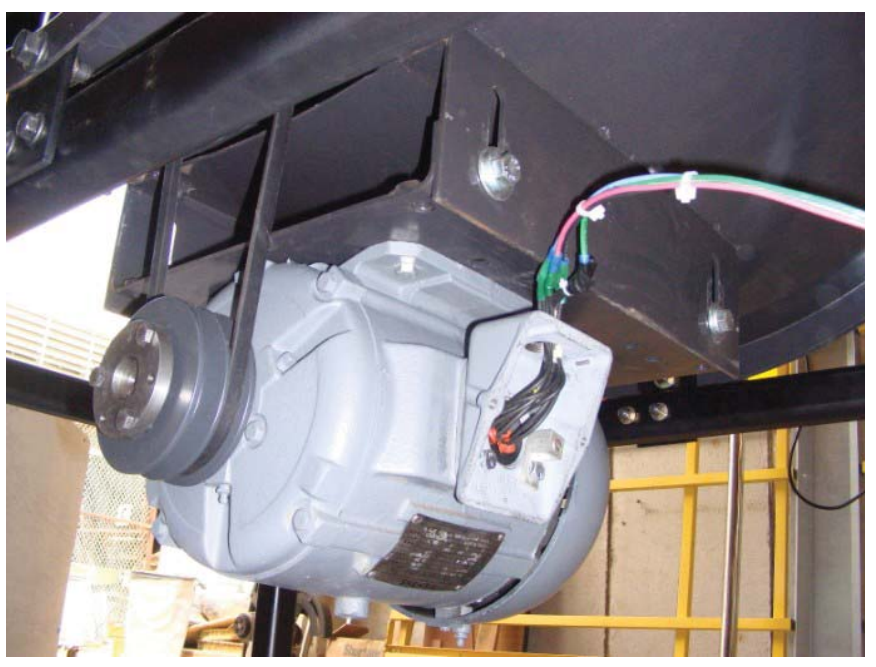

Figure 10. Installation of motor to the underside of fan.

The second part of the wind tunnel is the chamber itself where the wind energy capture device is installed. The AutoCAD drawing of the chamber can be seen in Figure 5 and Figure 6. A wind turbine in a representative chamber is shown in Figure 11. Two chambers will be constructed such that a greater wind speed can be achieved in the small 
chamber and larger turbines can be housed in the larger chamber.

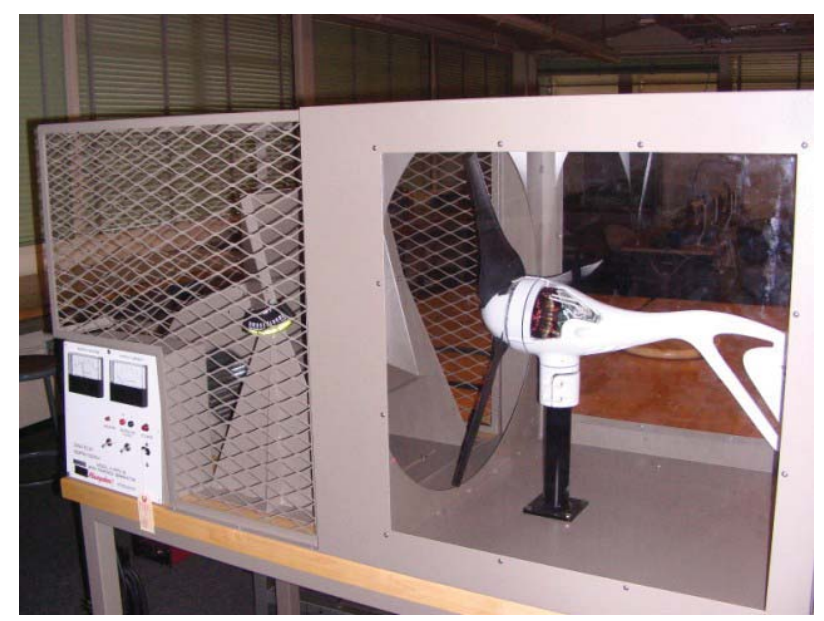

Figure 11. The wind turbine in a wind tunnel chamber

Shown in Figure 12 are the connection boxes constructed to allow measurements of motor current when required and of the VFD. These are fused for protection of the motor and VFD as well as to prevent overspeed of the fan. The VFD will be controlled using the STK600 AVR Microcontroller Development Board shown in Figure 13. This will allow the user to either manually request a particular wind speed or to program a varying wind speed time series that can be repeated from trial to trial. A Matrix Orbital key display (shown in Figure 14) is used as the input device such that a particular speed can be requested or simply an increase or decrease in speed can be requested. The key display has a 16-key key pad and a 20 column by 4 line text display with up to $19.2 \mathrm{Kbps}$ communications over RS232 or $\mathrm{I}^{2} \mathrm{C}$. The development board has a USB interface to PC for programming and control. It is powered either from USB bus or an external 10-15V DC power supply.

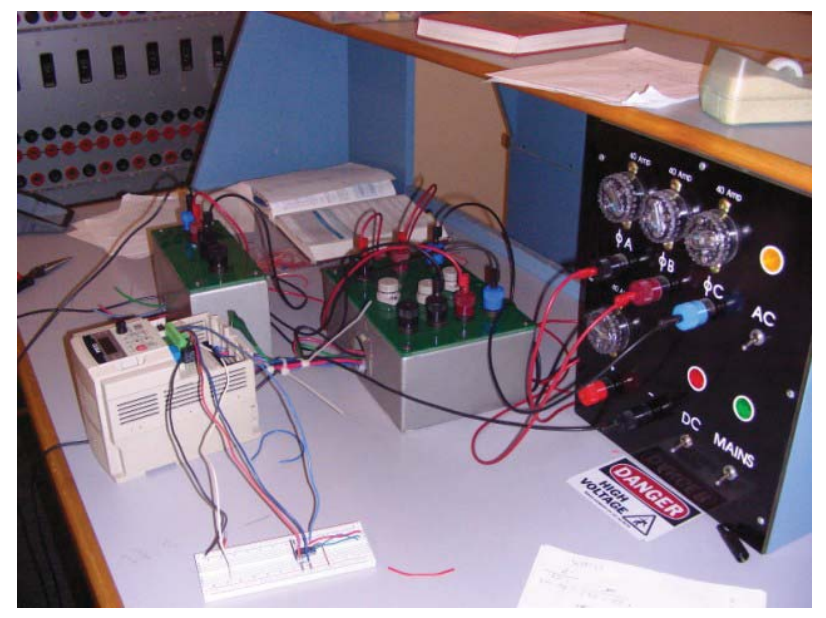

Figure 12. Connection boxes and Variable Frequency Drive

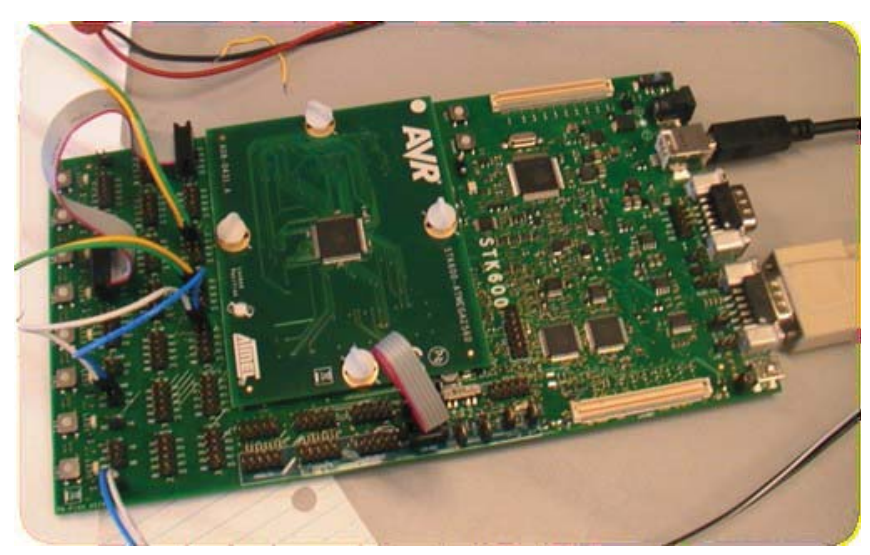

Figure 13. Atmel STK600 AVR Microcontroller Development Board

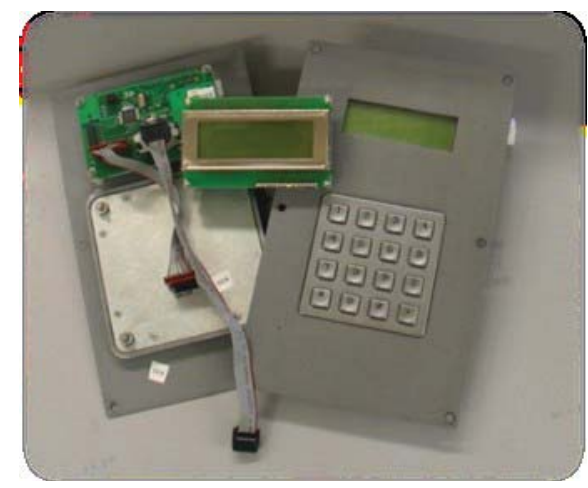

Figure 14. Matrix Orbital Key Display

The final piece required for control is an anemometer for wind speed measurement. This measured wind speed is fed back to the microcontroller and adjusted until the reference speed is reached. The anemometer is coupled with the Ultimeter 2000 to interpret the pulse train generated and convert this to a wind speed measurement. The anemometer and Ultimeter 2000 combination are shown in Figure 15.

The key pad interface has the following options; A) Measure Wind Speed, B) Change Wind Speed, C) Increment or Decrement motor speed and D) Input desired wind speed. The microcontroller processes the input and transmits the required commands to the VFD such that the desired action is implemented.

\section{Wind TUNNEL APPLICATIONS}

There are a number of potential applications for the developed Wind Tunnel. One area that will explored is the control systems used in small wind turbine MPPT algorithms and for battery charging. Another possible application is for testing of student designed small wind turbine blades and or generators using existing blade sets. Students will also explore open loop power generation and the effects of varying wind speeds on both open loop generation behavior and controlled closed loop behavior. One of the additional potential applications for this setup is in energy harvesting 
testing with various piezoelectric type sensors to determine the effectiveness and varying potential designs for low energy demand systems using wind energy.

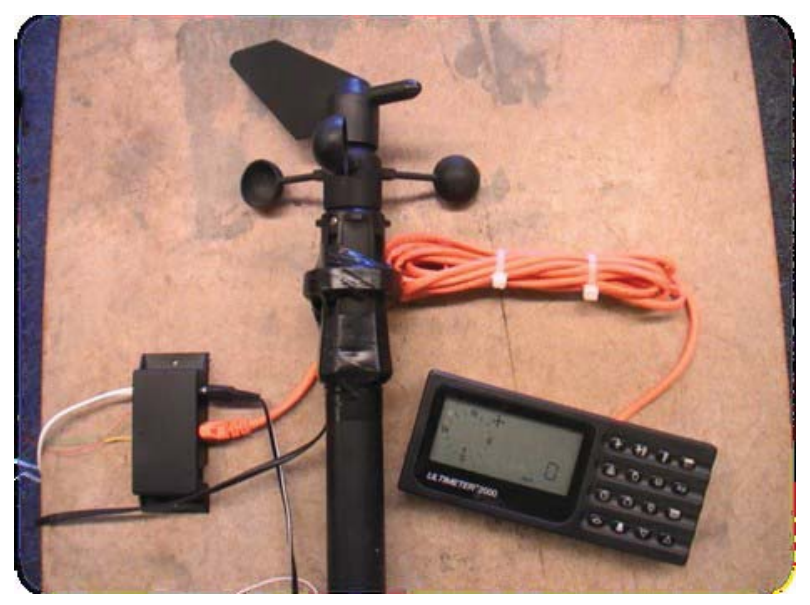

Figure 15. Anemometer and Ultimeter 2000.

\section{CONCLUSIONS}

A wind tunnel has been designed and developed for use in a laboratory setting for research and teaching purposes. The wind tunnel will allow electrical engineering students and faculty to have access to a local wind tunnel where a variety of testing and experimentation on wind energy generation technologies can be conducted. The wind tunnel allows repeatable and controlled environmental conditions that are unavailable in the field. Wind speeds of up to $20 \mathrm{~m} / \mathrm{s}(\sim 43$ $\mathrm{mph}$ ) can be produced using a 3 phase, $5 \mathrm{hp}, 208 \mathrm{~V}$ induction motor driving a 25,000 CFM 42 inch tube axial fan. A cross sectional area as large as 3.25 feet by 3.25 feet can be used at a wind speed of $14 \mathrm{~m} / \mathrm{s}(\sim 30 \mathrm{mph})$.

\section{REFERENCES}

[1]. L. Chang, R. Doraiswami, T. Boutot and H. Kojabadi, "Development of a wind turbine simulator for wind energy conversion systems", in Proc. Canadian IEEE CCECE 2000, vol. 1, Halifax, Canada, pp.550 2000.

[2]. D. S.L. Dolan, and P.W. Lehn, "Real-time wind turbine emulator suitable for power quality and dynamic control studies", presented at the Int. Conf. Power Systems Transients, IPST05, Montreal, Canada, Jun. 19-23 2005.

[3]. P.E. Battaiotto, R.J. Mantz, and P.F. Puleston, "A wind turbine emulator based on a dual DSP processor system," Contr. Eng. Pract., vol. 4, pp. 1261-1266, 1996

[4]. D. S.L. Dolan, and P.W. Lehn, "Simulation Model of Wind Turbine 3p Torque Oscillations due to wind shear and Tower Shadow", IEEE Transactions on Energy Conversion, Vol. 21, No. 3, pp 717-724, Sept 2006. 